\title{
Heterogeneity of the Angiogenic Response Induced in Different Normal Adult Tissues by Vascular Permeability Factor/Vascular Endothelial Growth Factor
}

\author{
Anna Pettersson, Janice A. Nagy, Lawrence F. Brown, Christian Sundberg, \\ Ellen Morgan, Steven Jungles, Robert Carter, Jose E. Krieger, Eleanor J. Manseau, \\ V. Susan Harvey, Isabelle A. Eckelhoefer, Dian Feng, Ann M. Dvorak, \\ Richard C. Mulligan, and Harold F. Dvorak \\ Department of Pathology (JAN, LFB, CS, EM, EJM, VSH, IAE, DF, AMD, HFD), Beth Israel Deaconess Medical \\ Center, and the Howard Hughes Medical Institute, Children's Hospital, and Harvard Institute of Human Genetics \\ (AP, SJ, RC, JEK, RCM), Harvard Medical School, Boston, Massachusetts 02215
}

\begin{abstract}
SUMIMARY: Vascular permeability factor/vascular endothelial growth factor (VPF/VEGF) is an angiogenic cytokine with potential for the treatment of tissue ischemia. To investigate the properties of the new blood vessels induced by VPF/VEGF, we injected an adenoviral vector engineered to express murine VPF/NEGF ${ }^{164}$ into several normal tissues of adult nude mice or rats. A dose-dependent angiogenic response was induced in all tissues studied but was more intense and persisted longer (months) in skin and fat than in heart or skeletal muscle ( $\leq 3$ weeks). The initial response (within 18 hours) was identical in all tissues studied and was characterized by microvascular hyperpermeability, edema, deposition of an extravascular fibrin gel, and the formation of enlarged, thin-walled pericyte-poor vessels ("mother" vessels). Mother vessels developed from preexisting microvessels after pericyte detachment and basement membrane degradation. Mother vessels were transient structures that evolved variably in different tissues into smaller daughter vessels, disorganized vessel tangles (glomeruloid bodies), and medium-sized muscular arteries and veins. Vascular structures closely resembling mother vessels and each mother vessel derivative have been observed in benign and malignant tumors, in other examples of pathological and physiological angiogenesis, and in vascular malformations. Together these data suggest that VPF/NEGF has a role in the pathogenesis of these entities. They also indicate that the angiogenic response induced by VPF/VEGF is heterogeneous and tissue specific. Finally, the muscular vessels that developed from mother vessels in skin and perimuscle fat have the structure of collaterals and could be useful clinically in the relief of tissue ischemia. (Lab Invest 2000, 80:99-115).
\end{abstract}

$A$ ngiogenesis plays a central role in many important disease processes (Brown et al, 1997; Dvorak et al, 1995; Folkman, 1995; Senger et al, 1993), and it is widely anticipated that modulation of angiogenesis (inhibition in tumors, stimulation in tissues with vascular insufficiency) will provide therapeutic benefit (Bauters et al, 1994; Boehm et al, 1997; Colville-Nash and Willoughby, 1997; Folkman, 1997; Giordano et al,

\section{Received October 28, 1999.}

This work was supported by United States Public Health Service National Institutes of Heath Grants CA-50453 (to HFD), AI-33372 (to RCM and $A M D$ ), and HL-59316, by funding from the Howard Hughes Medical Institute (to RCM) and by funding from the National Foundation for Cancer Research (to HFD). AP received fellowship support from the Wenner-Gren Foundation, Stockholm, Sweden.

The contributions of the first and second authors were equal.

Present address for JEK: Heart Institute, University of Sao Paulo School of Medicine, Sao Paulo, Brazil.

Address reprint requests to: Dr. Harold F. Dvorak, Department of Pathology, Beth Israel Deaconess Medical Center, Boston, MA 02215. Fax: (617) 667-2943; E-mail: hdvorak@caregroup.harvard.edu
1996; Hanahan, 1998; O’Reilly et al, 1997; Takeshita et al, 1996). It is hoped, for example, that the introduction of angiogenic cytokines into ischemic tissues with viral or other vectors will stimulate the formation of new blood vessels that will benefit patients with intermittent claudication or coronary heart disease. Of the many cytokines that possess angiogenic activity, vascular permeability factor/vascular endothelial growth factor (VPF/NEGF) stands out because of its potency, its selectivity for vascular endothelium, and its consistent overexpression in many malignant tumors and in other clinical situations in which angiogenesis is critical, such as wound healing and chronic inflammation (Brown et al, 1997; Dvorak et al, 1995; Senger et al, 1993). Encouraging results have been reported in animals whose ischemic tissues have been treated with VPF/VEGF or with its encoding DNA (Bauters et al, 1994; Isner et al, 1996; Pearlman et al, 1995; Takeshita et al, 1995). However, the utility of this approach in patients remains controversial (Brower, 1999; Henry, 1998; Isner and Asahara, 1999; Losordo et al, 1998; Ware and Simons, 1997). 
The goal of this study was to investigate the character and kinetics of the angiogenic response induced by VPF/VEGF. To that end, we engineered an adenoviral vector to express VPF/VEGF and studied the response elicited when it was injected into several different normal adult tissues. We report here that VPF/VEGF induced brisk angiogenesis in skeletal muscle, myocardium, peritoneum, perimuscular fat, and flank and ear skin. The initial response was identical in all tissues studied: increased microvascular permeability to plasma proteins, clotting of extravasated plasma fibrinogen, deposition of a provisional fibrin gel extravascular matrix, and formation of enlarged, thin-walled, pericyte-poor vessels ("mother" vessels) that were derived from much smaller preexisting microvessels. Thereafter, angiogenesis proceeded differently in different tissues. Within a few days, mother vessels in skeletal muscle and myocardium divided into smaller caliber daughter vessels or formed disorganized vessel tangles (glomeruloid bodies) similar to those found in certain highly malignant brain tumors. However, the entire angiogenic response within muscle was short lived and had largely resolved by 3 weeks. In skin and fat, mother and daughter vessels and glomeruloid structures developed with even greater intensity, but, in addition, some mother vessels acquired a muscular coat and developed into vessels that closely resembled medium-sized arteries and veins. Vessels of this type also resembled the collateral vessels described in ischemic hearts (Buschmann and Schaper, 1999; Cohen, 1985) and persisted indefinitely.

\section{Results}

\section{The Initial Response to Adeno-vpf/vegf Infection: Microvascular Leakage, Tissue Edema, and Fibrin Deposition}

An adenoviral vector engineered to express murine VPF/VEGF ${ }^{164}$ (adeno-vpf/vegf) under the control of a cytomegalovirus promoter was injected into skeletal muscle, skin, heart, and peritoneal cavity of immunodeficient adult nude mice or rats. Immunodeficient animals were used to avoid the strong immune response that adenoviral vectors evoke in immunocompetent animals. Within hours of injection, infected host cells expressed abundant VPF/VEGF mRNA and continued to do so for at least 10 days (Fig. 1). Not unexpectedly, VPF/VEGF induced an early increase in microvascular permeability to plasma proteins with consequent tissue edema, extravascular clotting of extravasated plasma fibrinogen, fibrin deposition, and
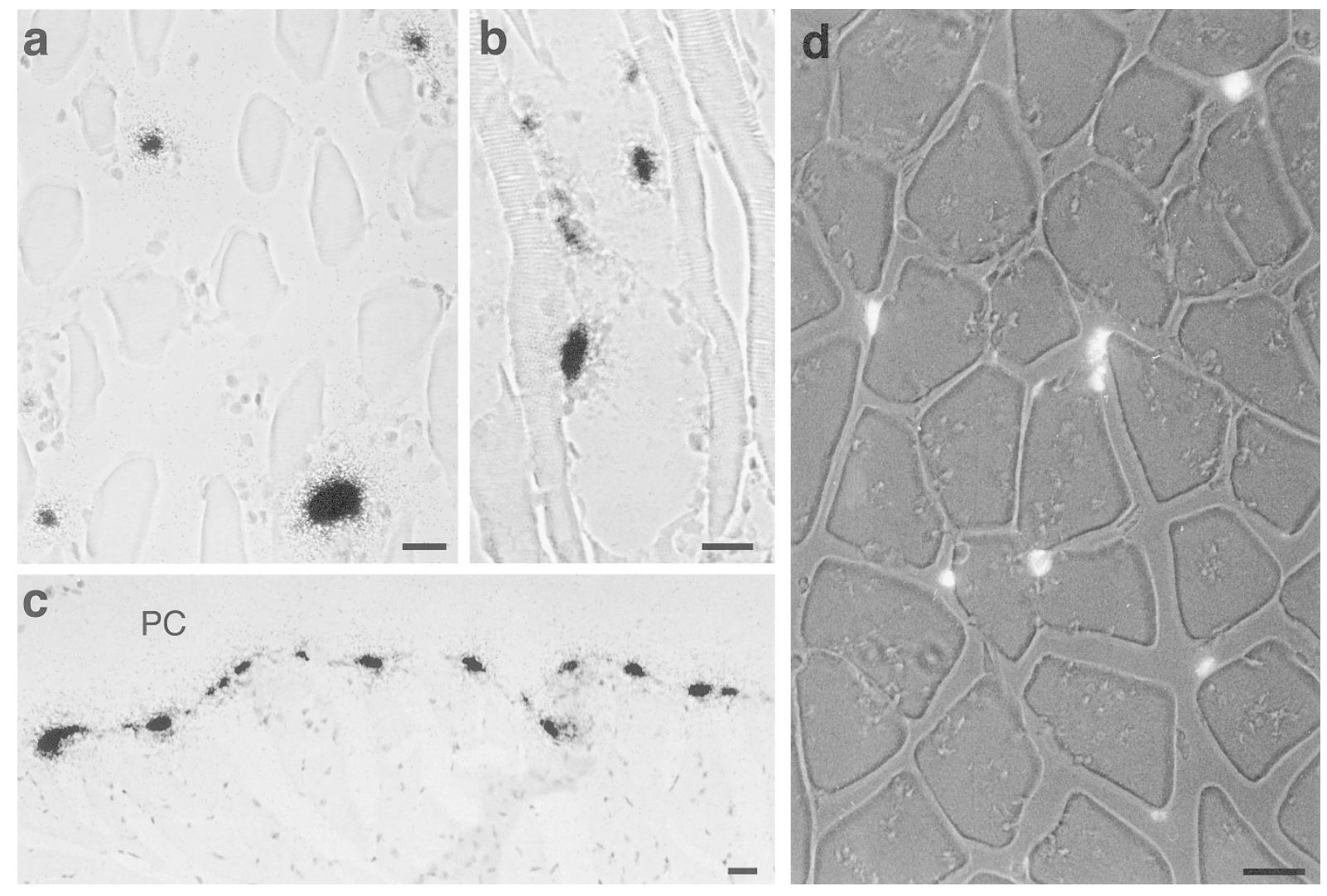

\section{Figure 1.}

$\mathrm{a}-\mathrm{c}$, In situ hybridization with ${ }^{35}$ S-labeled antisense probes for vascular permeability factor/vascular endothelial growth factor (VPF/VEGF) mRNA in anterior tibialis muscle (cut in cross section in a, in longitudinal section in b) and peritoneal wall (c) of nude mice at 5 and 4 days after im or ip injection of adenovirus expressing VPF/NEGF ${ }^{164}$ (adeno-vpf/vegf), respectively. a and b, Positive cells are located adjacent to or between muscle cells, which are themselves negative. In c, mesothelial cells lining the peritoneal cavity are positive for VPF/VEGF mRNA, whereas underlying muscle cells are negative. d, Fluorescence microscopy of anterior tibialis muscle of a nude mouse one day after im injection of adeno-green fluorescent protein (gfp). As in a and b, cells expressing gfp are interstitial cells. Bars, $25 \mu \mathrm{m}$. 
a strong angiogenic response (Figs. 2-5) (Dvorak et al, 1999). The intensity of the response was proportional to the dose of injected virus over a hundred-fold range $\left[2.5 \times 10^{6}\right.$ to $2.5 \times 10^{8}$ plaque-forming units (pfu)]. Equivalent doses of control adenoviral vectors engineered to express lacZ or green fluorescent protein (gfp; Fig. 1d) induced no detectable gross or microscopic response in any of the tissues studied.

\section{Generation and Properties of Mother Vessels}

The angiogenic response induced by adeno-vpf/vegf was qualitatively similar for the first 3 days in all of the tissues studied and was characterized by a striking early and progressive enlargement of microvessels (Figs. 3-6). These enlarging microvessels were embedded in a matrix of protein-rich edema fluid and fibrin (Figs. 3, g-i and k; 4, a and b; 5). They became sinusoidal structures, comparable in size to small or medium-sized arteries or veins, but they lacked a muscular coat and possessed few pericytes (Figs. 3-6). Enlarged endothelial cell (EC) nuclei protruded into the lumens of these vessels (Figs. 4 and 5, c, i, and $\mathrm{j}$ ), rendering the luminal surface irregular and therefore likely to cause turbulent blood flow (Cohen, 1985). Following Paku and Paweletz (1991), we have called these enlarged vessels "mother" vessels. Mother vessels continued to develop over the next 2-3 days in muscle and for somewhat longer at skin injection sites.

The kinetics of mother vessel formation were followed in ear skin. By 18-24 hours, the mean vessel cross-sectional area had increased by $\geq 3$ - to 4 .5-fold, the mean vessel perimeter by $\sim 2$-fold, and the percent of dermis occupied by microvessels by nearly 4to $>7$-fold (Table 1). Also, the ratio of numbers of EC to vessel area had declined 2- to 4-fold, whereas the numbers of microvessels per dermal area had increased by less than 2-fold.

The EC lining mother vessels were, on average, noticeably thinned (Figs. 3- 7). However, EC displayed marked intra- and intercell variation in height. Areas of relatively normal cytoplasmic thickness containing prominent collections of vesiculo-vacuolar organelles (VVO) (Fig. 7, a and b) alternated with adjacent zones of marked cytoplasmic attenuation. Attenuated zones were sometimes fenestrated (Fig. 7c), but, overall, fenestrae occupied $\leq 0.75 \%$ of the perimeter of mother vessel EC. This is a significant increase above that found in normal skin and skeletal muscle microvessels in which fenestrae occupy $<0.10 \%$ of EC perimeter. However, it is substantially less than that found in microvessels that are generally classified as fenestrated; eg, $12 \%$ of the perimeter of mouse adrenal cortex microvessels is occupied by fenestrae (Feng et al, 2000).

Mother vessels were hyperpermeable to circulating ferritin (FE), a protein found in normal plasma and here used as a tracer of macromolecule extravasation. FE molecules can be directly visualized by transmission electron microscopy and were found to extravasate either by way of VVO or through fenestrae (Fig. 7, a-c) (Dvorak et al, 1996; Feng et al, 1996). Analysis of 570 interfaces between adjacent EC failed to find a single

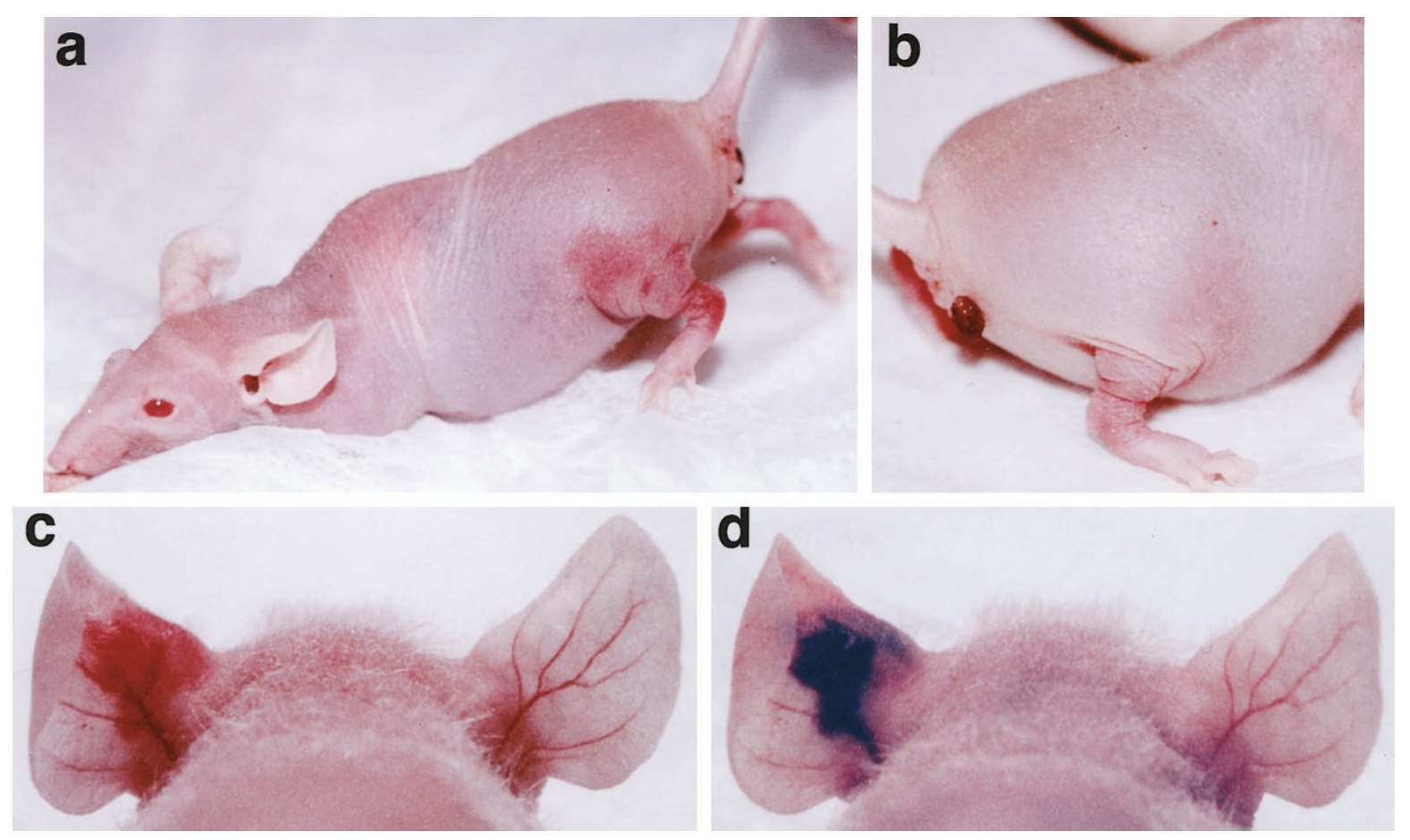

\section{Figure 2.}

Nude mice 8 days after injection of $2.5 \times 10^{8}$ pfu adeno-vpf/vegf into tibialis anterior muscle of the hind limbs (a and b) or 5 days after injection into the left ear (c and d). Note prominent tissue edema and new blood vessel formation. Evans blue dye was injected iv 20 minutes before photographing d; prominent bluing reflects leakage of dye-plasma protein complexes from locally hyperpermeable ear vessels. 

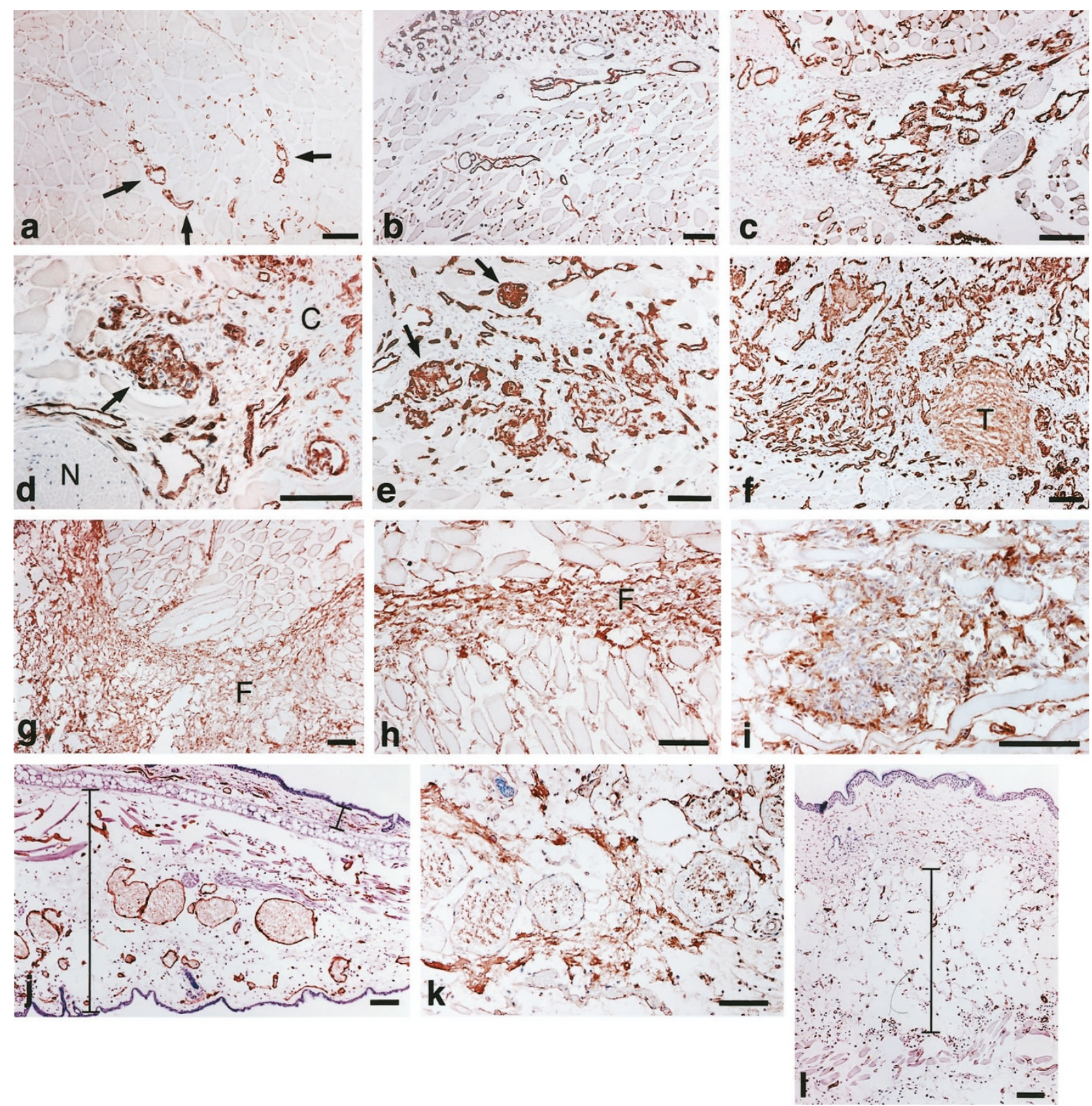

\section{Figure 3.}

Immunohistochemical staining of nude mouse leg muscle (a-i), ear ( $\mathrm{j}$ and $\mathrm{k}$ ), and flank skin (I) harvested at various times after im infection with adeno-vpf/vegf. a, Scattered, new, enlarged and strongly VEGFR-2-positive mother vessels (arrows) are evident 1 day after virus injection. b-f, Progressive increase in numbers of large and small CD31- (and VEGFR-2)-positive vessels at 3 days (b), 5 days (c and d), and 8 days (e and f) after im adeno-vpf/vegf injection. In d and e, note glomeruloid bodies (arrows). $T$, thrombosed mother vessel. $\mathrm{g}$-i, Fibrin deposits $(F$ at 8 days after im adeno-vpf/vegf injection. In $\mathrm{g}$ and $\mathrm{h}$, fibrin is for the most part deposited in interstices between muscle bundles, presumably because muscle contraction caused its extrusion from within muscle bundles. i, Collagenous connective tissue deposited between muscle bundles along with residual fibrin. $\mathrm{j}$ and $\mathrm{k}$, cross-sections at 4 days after injection of adeno-vpf/vegf. In j, note prominent CD31-positive mother vessels and extensive edema. Dermis below cartilage (bracketed line) is seven times thicker than that of normal dermis above cartilage. $\mathrm{k}$, Fibrin deposits are present in the edematous tissue between newly formed mother vessels. I, Flank skin injected 4 days earlier with adeno-vpf/vegf shows extensive edema (bracketed line) and new blood vessels just above the muscle layer. Bars, $100 \mu \mathrm{m}$.

instance in which inter-EC clefts were widened; moreover, inter-EC junctions were consistently closed and did not admit FE (Fig. 7b) (Dvorak et al, 1996; Feng et al, 1996, 1997). In contrast to mother vessels, very little FE extravasated from normal microvessels located a short distance away from sites of adeno-vpf/ vegf injection or in tissues injected with a control adenoviral vector bearing the lacZ gene.

\section{Origin of Mother Vessels from Individual Smaller Microvessels}

Several possibilities were considered for the origin of mother vessels: de novo formation from angioblasts (Asahara et al, 1997; Springer et al, 1998), generation from preexisting arteries or veins by shedding of their muscular coats, fusion of two or more smaller vessels, or derivation from the enlargement of individual pre- 

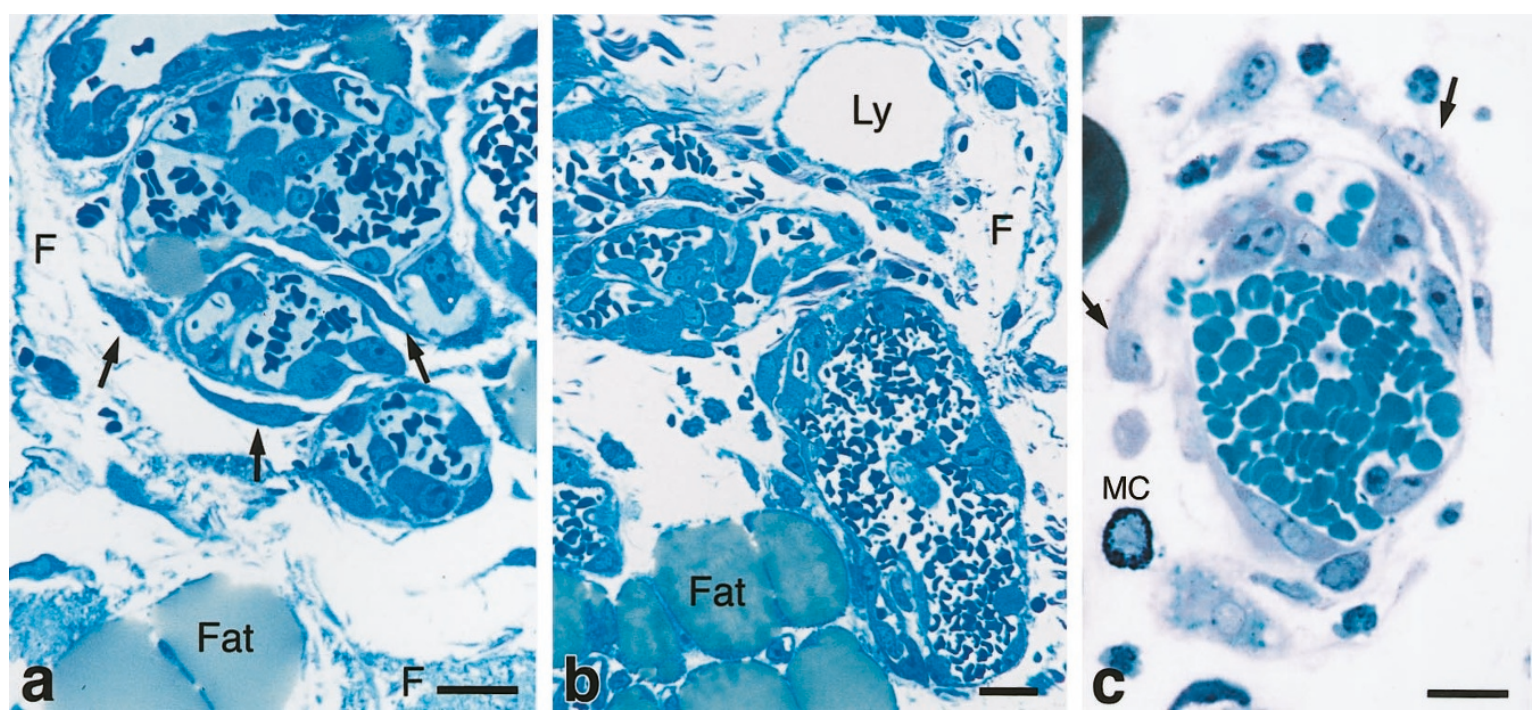

Figure 4.

One-micrometer thick, Giemsa-stained Epon sections illustrating leg muscle ( $a$ and b) and ear skin (c) of mice injected with adeno-vpf/vegf. a and b, Leg muscle 5 days after im adeno-vpf/vegf. Note fibrin $(F)$ and mother vessels that are undergoing bridging by intraluminal projection of activated endothelial cell (EC) processes, which divide the original lumen into multiple smaller channels. Arrows indicate pericytes. Ly, lymphatic vessel. C, Transluminal EC bridging illustrated in an ear vessel 3 days after intradermal adeno-vpf/vegf. Arrows indicate two activated pericytes. MC, mast cell. Bars, $15 \mu \mathrm{m}$.

cursor microvessels. To distinguish among these possibilities, we made use of $1-\mu \mathrm{m}$ Epon sections to follow the generation of mother vessels during the first 24 hours after adeno-vpf/vegf injection into ear skin. Primitive cells that might correspond to angioblasts were not observed during this time frame. Preexisting medium-sized arteries and veins remained identifiable and did not undergo detectable loss of muscular coat as mother vessels developed. Moreover, the numbers of newly formed mother vessels greatly exceeded those of preexisting arteries and veins. Morphometric analysis revealed that the mean distance between adjacent vessels did not change significantly during the first 21 hours after adeno-vpf/vegf injection because vessel enlargement, which might have been expected to draw vessels closer to each other, was offset by accumulating interstitial edema. This last finding along with the thinning of EC with mother vessel formation argues against the possibility that mother vessels arose from the fusion of adjacent smaller vessels.

Lack of evidence for other possibilities and some additional findings indicate that mother vessels arose from the enlargement of individual preexisting microvessels, possibly venules. The thinning of EC that accompanied mother vessel formation suggests that mother vessels formed, at least initially, from the spreading of preexisting EC over an increased surface area. Consistent with this interpretation, EC proliferation was insubstantial during the first 24 hours after adeno-vpf/vegf injection as judged by only minimal changes in EC frequency per vessel (Table 1) and by only occasional proliferating cell nuclear antigen staining of EC nuclei (data not shown). A second piece of evidence was provided by striking changes in expression of vascular permeability factor/vascular endothelial growth factor receptor (VEGFR)-2 (KDR, flk-1). The microvessels supplying normal skeletal muscle expressed little or no detectable VEGFR-2 as determined by in situ hybridization or by a specific antibody. However, within 24 hours of adeno-vpf/vegf injection, EC lining normal capillaries, venules, and mother vessels (but not arterioles or arteries) became strongly positive for VEGFR-2 mRNA (not shown) and protein (Fig. 3a). Thus, at sites of VPF/NEGF expression, capillaries, venules, and mother vessels (but not arterioles) shared a common property, increased expression of VEGFR-2. Finally, taller portions of mother vessel cytoplasm contained prominent VVO (Fig. 7a), structures that are more typical of venules than of capillaries (Dvorak et al, 1996).

\section{Mechanisms of Mother Vessel Formation}

We next considered the mechanisms by which mother vessels might develop from smaller microvessels. At least three major impediments must be overcome if microvessels are to enlarge in any tissue. One impediment, that of the constrictive collagenous extracellular matrix typical of many normal adult tissues, was mitigated within a matter of hours as a consequence of VPF/VEGF-induced microvascular hyperpermeability. This led to extravasation of plasma proteins, tissue edema, and deposition of a fibrin-rich provisional matrix.

The pericytes that normally envelop microvessels and maintain vascular tone afford a second impediment to vessel enlargement. However, by 18-24 hours the ratio of pericytes to numbers of EC and to vessel area and perimeter declined significantly, whereas the number of pericytes per vessel remained static (Table 1). Thus, unlike EC, pericytes did not keep up with vessel enlargement by spreading to cover a larger surface nor did they divide. In addition, 

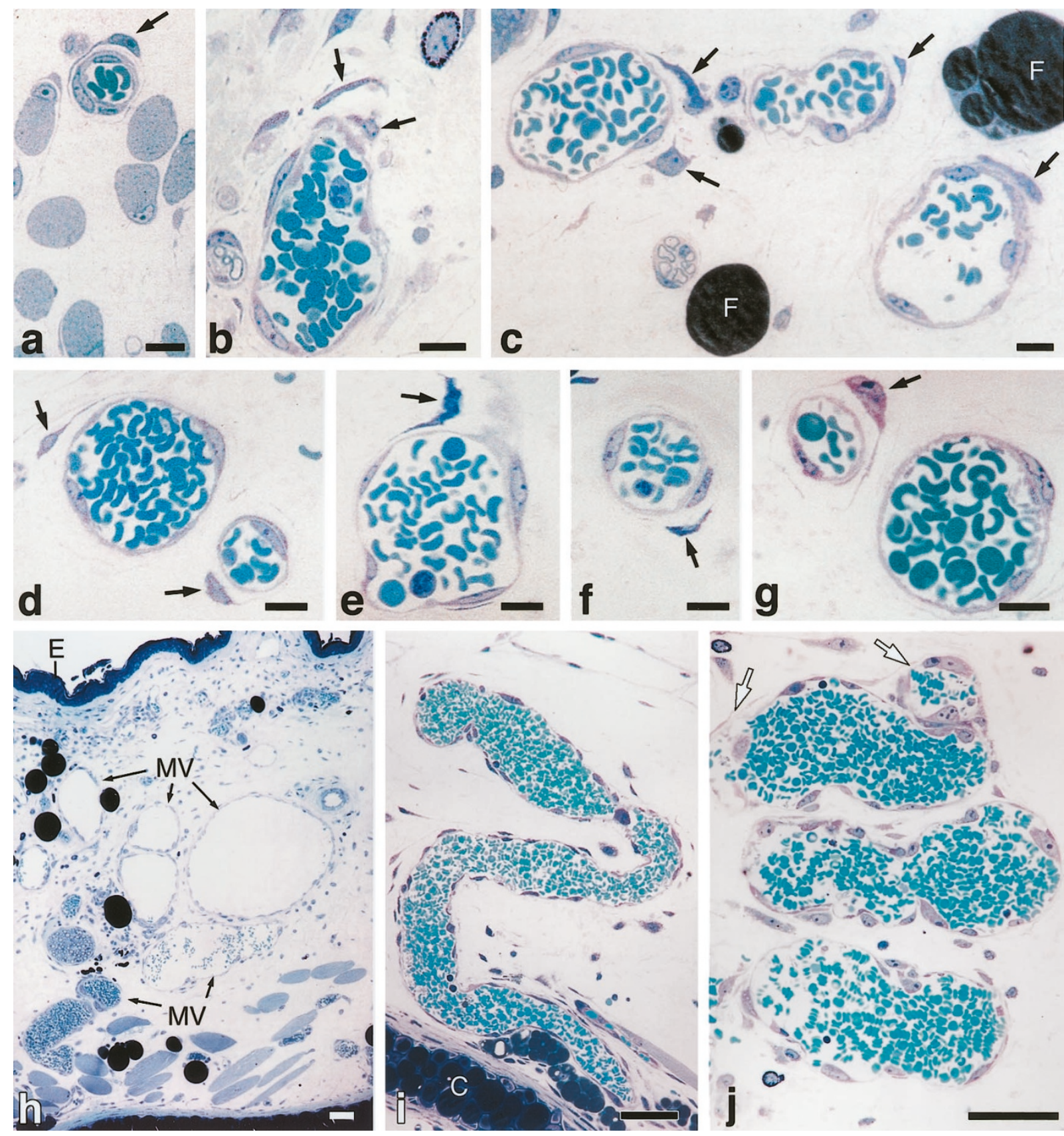

\section{Figure 5.}

Vessels in ear skin at 18 hours $(a-g), 3$ days ( $i$ and j) and 4 days (h) after local injection of adeno-vpf/vegf. a, Normal sized venule with slightly detached pericyte (arrow). Note extensive edema separating adjacent muscle fibers. b-g, Evolving mother vessels illustrating striking vessel enlargement, EC activation (enlargement, prominent nucleoli), and pericytes (arrows) in various stages of detachment from vessels. Some pericytes (c, e, and f) stain darkly, possibly indicating cell damage. $F$, fat. h, Low power view of ear skin. Note extensive collection of mother vessels (MV). Deeper vessels adjacent to the underlying cartilage are filled with red blood cells, whereas more superficial mother vessels contain few such cells or appear empty. Note persistent edema that greatly thickens the dermis and separates muscle cells just above the cartilage. $E$, epidermis. i, Portion of a mother vessel cut in longitudinal section illustrating serpentine pattern and irregular luminal surface. $C$, ear cartilage. j, Higher power magnification captures three sections through mother vessels, illustrating highly irregular luminal surface and EC bridging to form additional lumens (arrows). Bars: a-g, $10 \mu \mathrm{m} ; \mathrm{h}, 500 \mu \mathrm{m} ; \mathrm{i}$ and j, $50 \mu \mathrm{m}$.

many pericytes detached from developing mother vessels, though often remaining recognizable nearby (Figs. 4, a and c, and 5, a-g).

A third impediment to microvessel enlargement is that provided by the vascular basement membrane. Basement membranes are noncompliant (inelastic) structures that limit the enlargement of vascular diameter to $\sim 15 \%$ (corresponding to an $\sim 30 \%$ increase in area) (Swayne and Smaje, 1989; Swayne et al, 1989). Therefore, structural changes in the vascular basement membrane were necessary to accommodate the mean 3- to 4.5-fold increase in microvessel area that developed within 18-24 hours of adeno-vpf/vegf injection into ear skin (Table 1). To determine whether basement membranes underwent structural changes in the course of mother vessel generation, we per- 

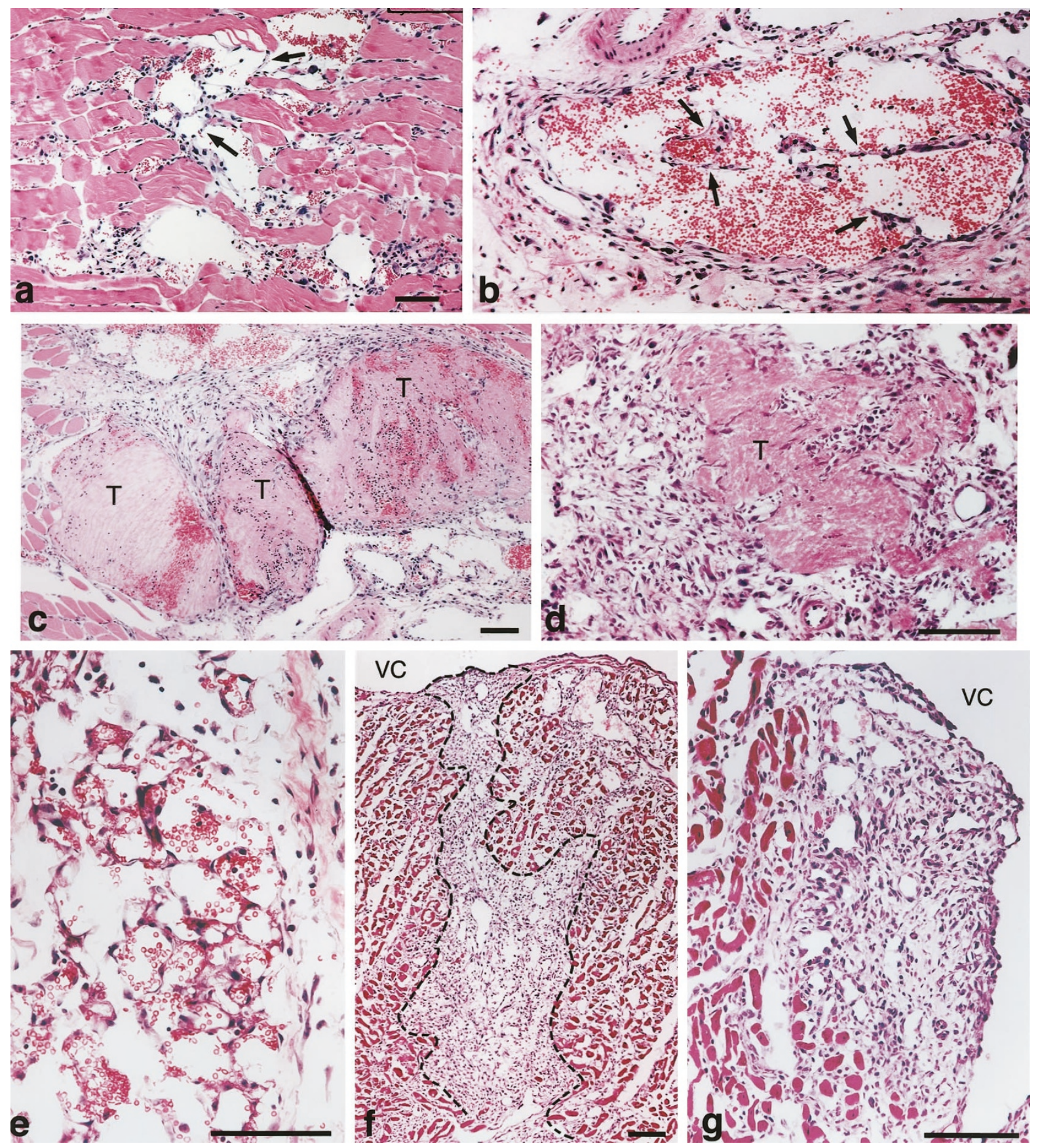

\section{Figure 6.}

Hematoxylin and eosin-stained sections illustrating blood vessel and stroma formation in leg muscles $(a-d)$ and mesentery (e) of nude mice and in myocardium ( $f$ and g) of nude rats after injection of adeno-vpf/vegf. a-d, 8 day injection sites with prominent mother vessels. In a and b, EC processes project into and bridge vascular lumens (arrows). $c$ and d, Thrombosed mother vessels $(T$ ) with destruction of vessel walls and accumulation of fibrous connective tissue. e, Normally fatty mesentery is replaced by numerous, thin-walled vessels 4 days after ip injection of adeno-vpf/vegf. $f$ and $\mathrm{g}$, Left ventricle 5 days after injection of adeno-vpf/vegf into myocardium. Note numerous new, thin-walled blood vessels embedded within newly formed fibrous connective tissue. $V C$, ventricular cavity. Bars, $100 \mu \mathrm{m}$.

formed immunohistochemistry with antibodies to laminin, an important basement membrane component. In normal mouse ear skin, microvascular basement membranes stained strongly with this antibody (Fig. 8a); however, staining was greatly reduced in developing mother vessels, sometimes focally and in other cases circumferentially (Fig. 8, b-d). This loss of laminin staining reflects at least partial degradation of basement membrane. Consistent with this possibility,
VPF/VEGF is known to stimulate the expression of EC proteases including both plasminogen activators and matrix metalloproteases (Pepper et al, 1991; Unemori et al, 1992). Proteolytic degradation of vascular basement membranes has long been associated with angiogenesis and has been thought to be essential for sprout formation (Grant and Kleinman, 1997). Our findings add an additional consequence of basement membrane degradation, that of permit- 


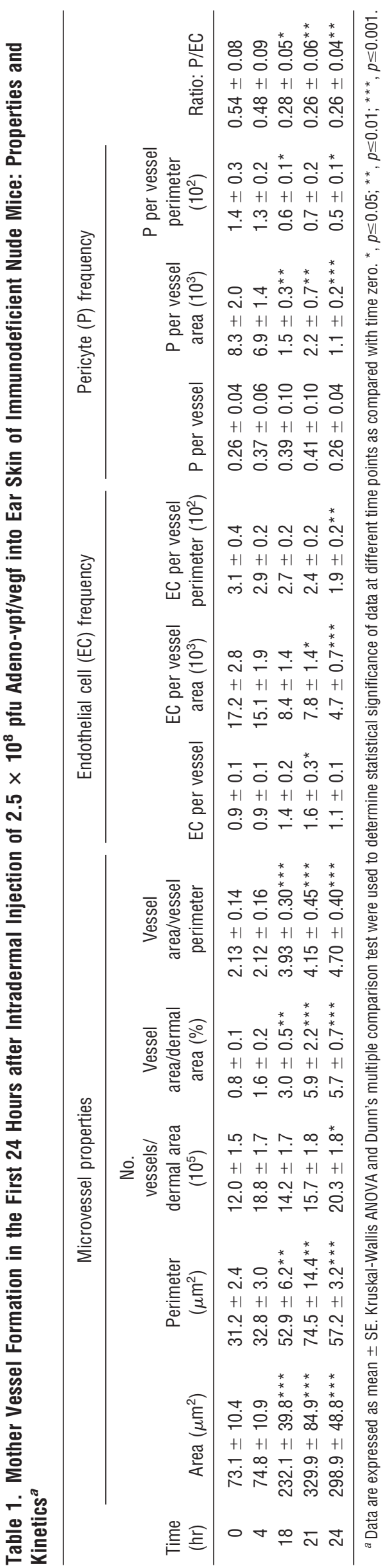

ting the vascular expansion necessary to form mother vessels.

\section{Divergent Kinetics and Pathways of Mother Vessel Evolution in Different Tissues}

Mother vessels were transitional forms that generally did not persist as such for more than a few days. Some mother vessels thrombosed (Figs. 3f and 6, c and d) but the great majority evolved along one of several alternative pathways (Figs. 8e and 9-12). Many mother vessels divided into smaller "daughter" vessels by sprouting or by projection of EC cytoplasmic processes into and across mother vessel lumens, forming transluminal EC "bridges" (Figs. 4; 5j; 6, a, b, and e; 12). These bridges divided blood flow into smaller sized channels that over the course of several days separated from each other to form smallercaliber daughter vessels (Figs. $8 \mathrm{e}$ and 12). Mother vessels also evolved along a less well-characterized pathway, forming disorganized vascular structures with multiple lumens that closely resemble the glomeruloid bodies found in glioblastoma multiforme brain tumors (Fig. 3, d and e; 9; 11, a and b; 12) (Lantos et al, 1997; Plate et al, 1992).

The angiogenesis induced by adeno-vpf/vegf in skeletal and heart muscle was relatively short lived. Fibroblasts migrated into the provisional fibrin matrix and gradually replaced it with collagenous stroma (Fig. $6, \mathrm{c}, \mathrm{d}, \mathrm{f}$, and $\mathrm{g}$ ) and the entire response had largely resolved by 3 weeks. In contrast, the angiogenic response in skin was much more intense than that which developed in either skeletal or heart muscle. Mother vessels were numerous (Fig. 5, h-j) and evolved into well-differentiated daughter vessels (capillaries and venules) that, unlike those in muscle, continued to function indefinitely (Fig. 8e). Numerous glomeruloid bodies formed (Fig. 9a), and, as in muscle (Fig. 9b), these resolved by as yet undetermined mechanisms over a period of several weeks. In addition, however, mother vessels in ear skin evolved along pathways that were not followed in skeletal muscle. Thus, many mother vessels retained their large size and over the course of 1-3 weeks acquired a smooth muscle coat and sometimes an internal elastica (Fig. 10, a and b). They thus differentiated into structures that closely resembled medium-sized arteries or veins. These muscular vessels persisted and continued to be perfused by blood through the latest time period studied, 3 months.

Mother vessels in ear skin evolved along yet another pathway, that of intussusception, a process distinct from transluminal bridging. Intussusception occurs in embryogenesis when "pillars" of connective tissue impinge from without on hollow, tubular structures (eg, a primary bronchus), causing focal invagination. This results in longitudinal splitting of the parent structure into smaller branched structures (eg, second or later generation bronchi) (Burri and Tarek, 1990; Patan et al, 1993). Similar invaginations of connective tissue were observed focally in mother vessels and also in mother vessels that had already begun to acquire a muscular 

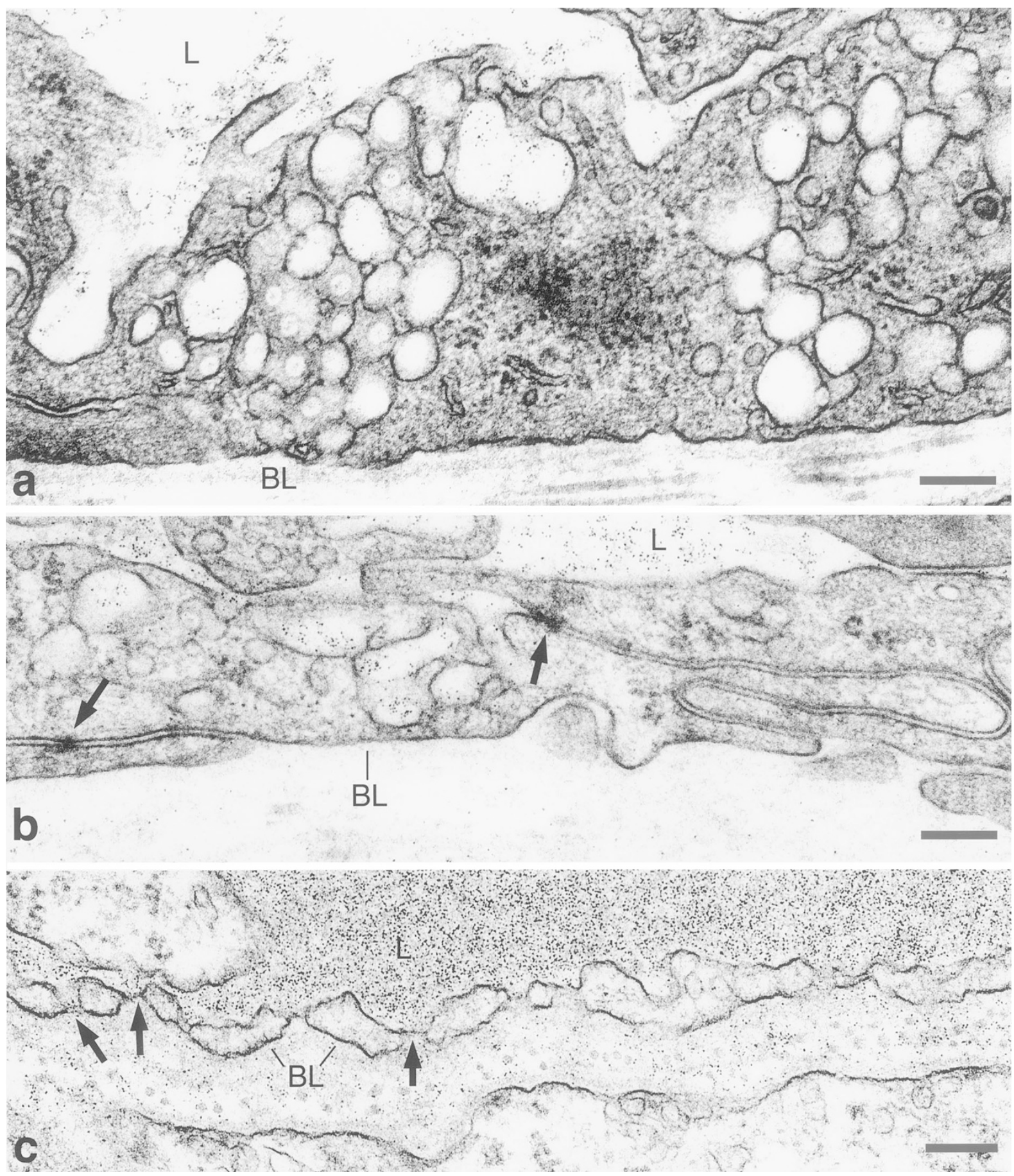

\section{Figure 7.}

Electron micrographs of newly formed, hyperpermeable vessels in mouse leg muscle 3 days after im injection of adeno-vpf/vegf and 20 minutes after iv injection of ferritin (FE) tracer. a and b, Multiple, individual FE molecules, visualized as small black particles, are evident within vesiculo-vacuolar organelle (VVO) vesicles and vacuoles. Some have extravasated into the basal lamina $(B L)$ and underlying interstitium. Inter-EC junctions (arrows) are normally closed and the serpentine inter-EC clefts are not widened. $c$, Passage of FE across fenestrated endothelium into the underlying basal lamina $(B L)$. Central arrow indicates a fenestral diaphragm; the other two arrows indicate fenestrae through which FE is passing. L, vascular lumen. Bars, $200 \mathrm{~nm}$.

coat (Fig. 10, c and d). Connective tissue cells of undetermined identity, perhaps pericytes, were often present in the connective tissue pillars. These may have contributed to intussusception by wrapping around vessels at discrete points and causing napkin ring-like constrictions that narrowed mother vessels and eventually led to their splitting into smaller daugh- ter vessels. Intravascular platelet-fibrin clots were commonly found to fill the residual vascular lumen at sites of extensive intussusceptive vessel narrowing (Fig. 10d) and likely contributed to the final stages of vessel splitting.

The finding of muscular vessels in ear skin provoked an extensive but unsuccessful search for similar ves- 

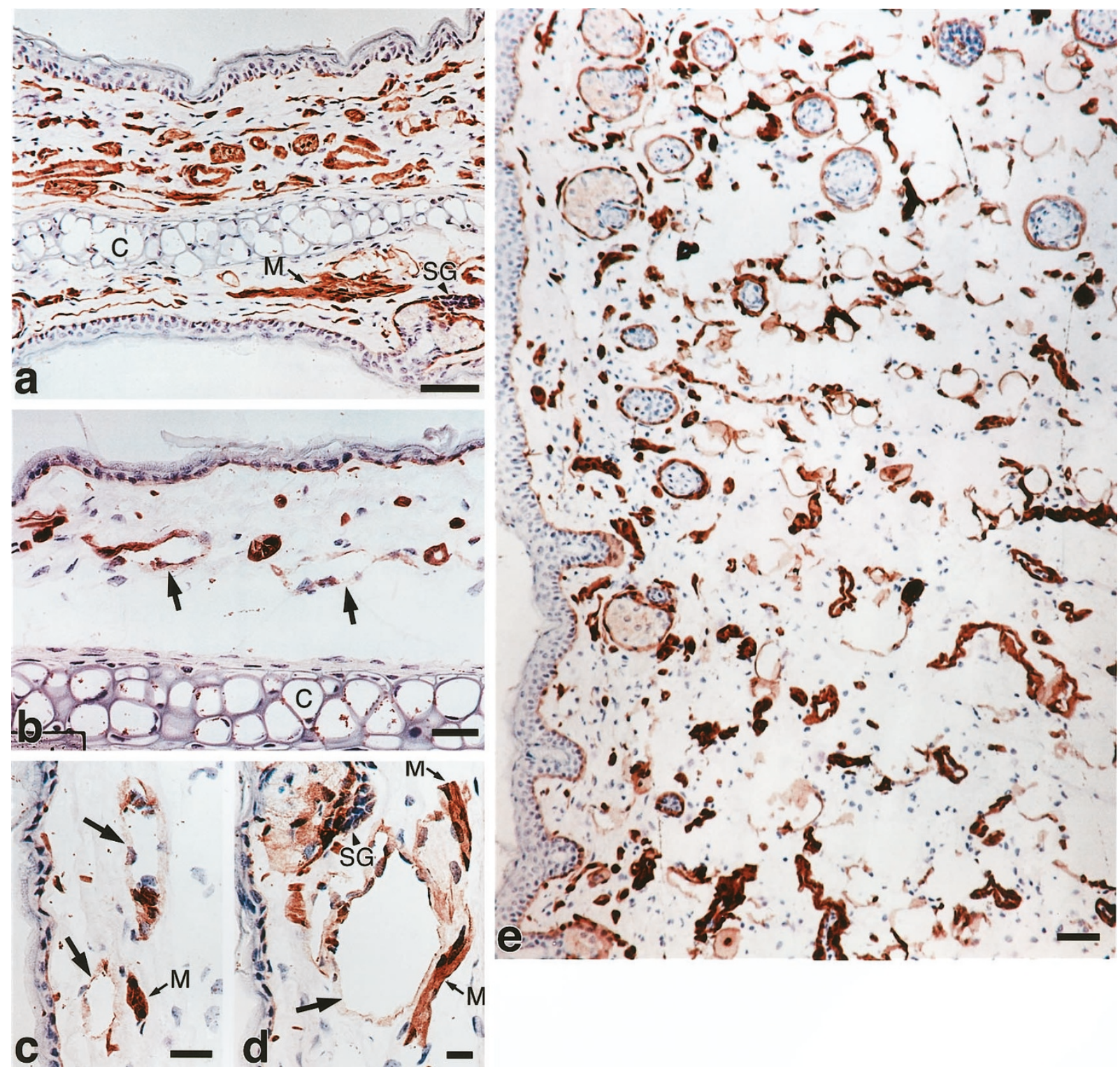

\section{Figure 8.}

Immunohistochemical staining for laminin in normal ear skin at time zero (a) and at 24 hours (b-d) and 28 days (e) after intradermal injection of adeno-vpf/vegf a, Cross section through normal ear with central cartilage $(C)$. All vascular basement membranes stain strongly for laminin as do scattered muscle fiber $(M)$ and sebaceous gland $(S G)$ basement membranes. Epidermal basement membrane stains weakly. b-d. Twenty-four hours after adeno-vpf/vegf injection, basement membranes of developing mother vessels show reduced or absent laminin staining (arrows). Loss of staining was patchy or in some cases circumferential. Skeletal muscle fiber $(M)$ and sebaceous gland $(S G)$ basement membrane staining is undiminished. E, Twenty-eight days after adeno-vpf/vegf injection, numerous small daughter vessels (normal appearing capillaries and venules) have formed, and these stain strongly and uniformly for laminin. Bars: $a, b, a n d ~ e, 50 \mu \mathrm{m} ; \mathrm{c}$ and d, 20 $\mu \mathrm{m}$.

sels at adeno-vpf/vegf injection sites in leg skeletal muscle. In the course of this search, we noted an intense angiogenic response in the fatty connective tissue overlying muscle bundles at sites of im injection of adeno-vpf/vegf (Fig. 11a); this response probably resulted from back leakage of adeno-vpf/vegf that had been injected into skeletal muscle. The angiogenic response in perimuscle fat was similar in intensity to that found in ear skin and included numerous mother and daughter vessels and glomeruloid bodies as well as occasional medium-sized muscular arteries and veins (Fig. 11, c and d). Daughter vessels and glomeruloid bodies largely resolved over several weeks and were replaced by fibrous connective tissue (Fig. 11b), whereas muscular arteries and veins persisted for months (Fig. 11, c and d).

\section{Discussion}

Adeno-vpf/vegf induced a dose- and time-dependent, tissue-specific angiogenic response in several different normoxic tissues of adult nude mice and rats (summarized schematically in Fig. 12). The initial response was qualitatively similar in all tissues studied, ie, skeletal muscle, myocardium, ear and flank skin, perimuscular fat, and peritoneal lining tissues. Within 

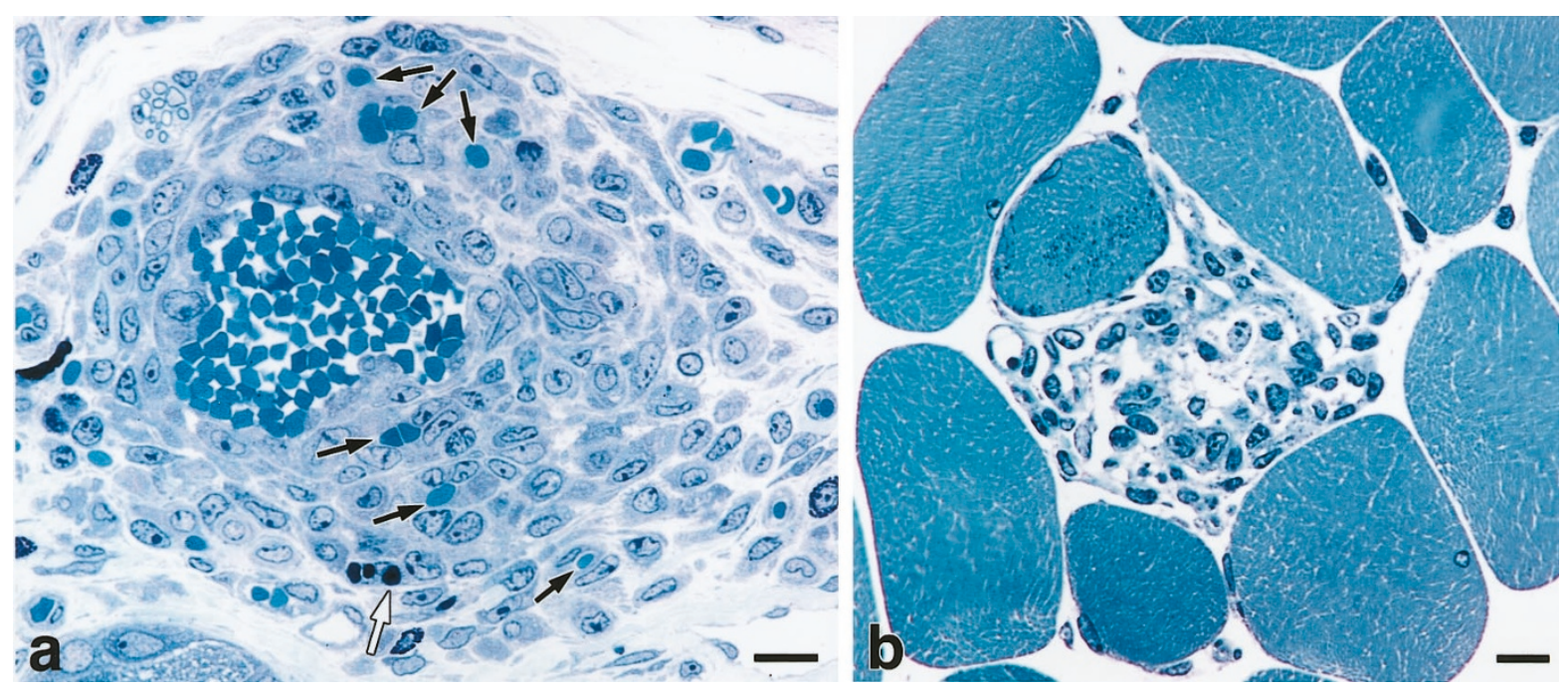

\section{Figure 9.}

a, Well developed glomeruloid body in ear skin 21 days after intradermal injection of adeno-vpf/vegf. Note major central vascular channel and multiple smaller channels (black arrows) filled with red blood cells. White arrow indicates an apoptotic body. b, Remnant of glomeruloid body in skeletal muscle 14 days after im injection of adeno-vpf/vegf. Bars, $15 \mu \mathrm{m}$.

18-24 hours, preexisting microvessels became hyperpermeable to plasma proteins, resulting in tissue edema and deposition of a proangiogenic fibrin gel matrix. These changes in extracellular matrix were accompanied by generation of enlarged, thin-walled, pericyte-poor, hyperpermeable, strongly VEGFR-2positive blood vessels, which we have called mother vessels. Vessels with similar morphology have been described in other examples of pathological angiogenesis and also in angiogenesis assays, both in vitro and in vivo, eg, after application of VPF/NEGF to chick embryos (Drake and Little, 1995), in cultures of polyoma virus-transformed EC (Pepper et al, 1996), in the collagen-nylon sandwich implant assay (Dellian et al, 1996), in tumor angiogenesis (Nagy et al, 1995; Paku and Paweletz, 1991; Warren, 1979; Warren et al, 1995), in psoriasis (Detmar et al, 1994), in wound healing (Brown et al, 1992), in vascular telangiectasias (port-wine stain), and in benign tumors (sinusoidal and cavernous hemangiomas) (McKee, 1996; Strutton, 1997). However, the rapidity (within 18 hours) with which mother vessels formed, the mechanisms responsible for their formation (pericyte detachment, basement membrane degradation), their hyperpermeability to plasma proteins, their participation as a consistent intermediate step in the angiogenic cascade, and their diverse evolution in different tissues have not heretofore been appreciated.

The mother vessels induced by adeno-vpf/vegf were for the most part transient structures that evolved over the course of a few days to a week into smaller daughter vessels (by sprouting, transluminal bridging, or intussusception), into glomeruloid bodies, and, in skin and perimuscle fat, into medium-sized arteries and veins. The mother vessels that appear early in the course of healing skin wounds are also transient, dividing into smaller vessels within a few days (Brown et al, 1992). Mother vessels are commonly observed in tumor angiogenesis and persist indefinitely in some malignant tumors and in vascular telangiectasias and certain hemangiomas. However, in other tumors, the EC lining mother vessels form transluminal bridges that divide mother vessels into smaller daughter vessels (Feng et al, 2000; Nagy et al, 1995), much as we have described here in the angiogenic response to adeno-vpf/vegf.

The vascular structures into which mother vessels evolved also have counterparts in malignant tumors, in vascular malformations, and in benign vascular tumors. Thus, glomeruloid bodies are a feature of glioblastoma multiforme, highly malignant brain tumors that express large amounts of VPF/VEGF (Lantos et al, 1997; Plate et al, 1992). Glomeruloid bodies are additionally found in glomeruloid hemangiomas and reactive angioendotheliomas. Also, clusters of mediumsized arteries and veins comprise arteriovenous hemangiomas (McKee, 1996; Mulliken and Young, 1988; Strutton, 1997; Vikkula et al, 1996). Springer et al (1998) have described "angiomas" in skeletal muscle into which they had introduced VPF/VEGFexpressing myoblasts. Taken together with other data (Brown et al, 1996; Chang et al, 1999; Takahashi et al, 1994), these findings suggest that VPF/NEGF has a role in the pathogenesis of all of these entities.

Although VPF/VEGF was strongly expressed for at least 10 days in all tissues studied, the resulting angiogenic response exhibited a significant degree of tissue specificity. The factors responsible for this tissue specificity are at present unknown but likely include differences in the pattern of cytokine and EC gene expression in different tissue microenvironments (Aird et al, 1997). However, another factor, the mechanical effects of skeletal and cardiac muscle contraction, must also be considered. We have already suggested that muscle contraction led to back leakage of im-injected adenovirus, resulting in the strong angiogenic response found in perimuscle fat. In addition, it is likely that muscle contraction was responsi- 


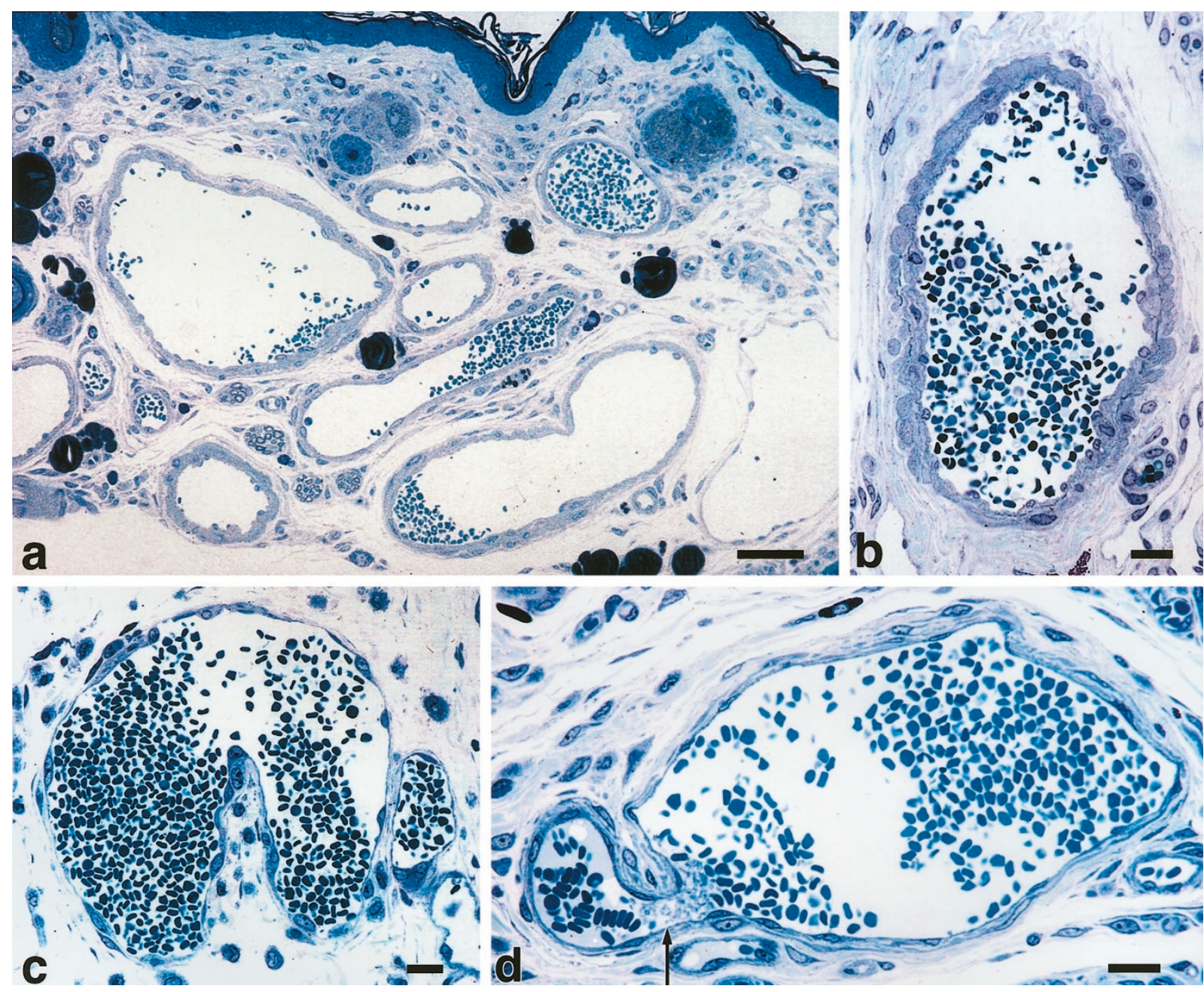

Figure 10.

One-micrometer thick, Giemsa-stained Epon sections of ear skin at various intervals after intradermal injection of adeno-vpf/vegf. a, Low power view of mouse ear skin at 35 days. Numerous, large, red blood cell-containing vessels are present, all of which but one (far right, a lymphatic) have acquired a muscular coat. Bands of fibrous connective tissue separate vessels. b. Higher power view of one such vessel, better illustrating bi-layered muscle cells in vessel wall as well as foci of elastic tissue (intermittent, thin, dark blue wavy line between cell layers). $c$ and d, Intussusception in a 4-day thin-walled vessel (c) and in a 21-day vessel (d) that has acquired an elementary muscle coat and is enveloped by fibrous connective tissue. Note intraluminal clot at point of vessel narrowing in d (arrow). Bars: a, $50 \mu \mathrm{m} ; \mathrm{b}-\mathrm{d}, 20$ $\mu \mathrm{m}$.

ble for the extrusion into the subcutis of much of the edema fluid and fibrin that originated from leaky blood vessels within skeletal muscle (Fig. 2). Muscle contraction may also have compressed thin-walled mother vessels, thereby impeding blood flow, compromising vessel viability, and cutting short the evolution of the angiogenic response within muscle. By contrast, in ears and in perimuscle fat, mother vessels developed in a microenvironment relatively protected from external compression and may therefore have been better able to persist and evolve into long-lasting daughter vessels and medium-sized arteries and veins.

The finding that VPF/NEGF-induced mother vessels may evolve into medium-sized arteries and veins suggests a relationship between angiogenesis and collateral vessel formation (also referred to as "arteriogenesis"). Angiogenesis and arteriogenesis have been thought to be distinct processes mediated by different mechanisms (Buschmann and Schaper,
1999; Cohen, 1985; Skalak et al, 1998). Thus, angiogenesis is thought to result from the action of cytokines on preexisting microvessels, leading to the formation of new capillaries and venules. Collateral vessels, on the other hand, are arterial structures that have been thought to develop from preexisting, minimally perfused arterioles as the result of mechanical forces, particularly circumferential wall stress (Cohen, 1985; Schaper, 1991; Schaper and Schaper, 1993). However, angiogenesis and arteriogenesis are not without certain obvious similarities. Thus, the tissue ischemia that leads to collateral formation also induces heart and skeletal muscle cells to overexpress VPF/NEGF ( Li et al, 1996). Further, vessel enlargement (mother vessel formation), an early step in VPF/NEGFinduced angiogenesis, has a counterpart in arteriogenesis in which early enlargement of precollateral vessels is thought to initiate circumferential wall stress (Cohen, 1985; Schaper and Schaper, 1993). Taken together, our findings raise the possibility that VPF/ 


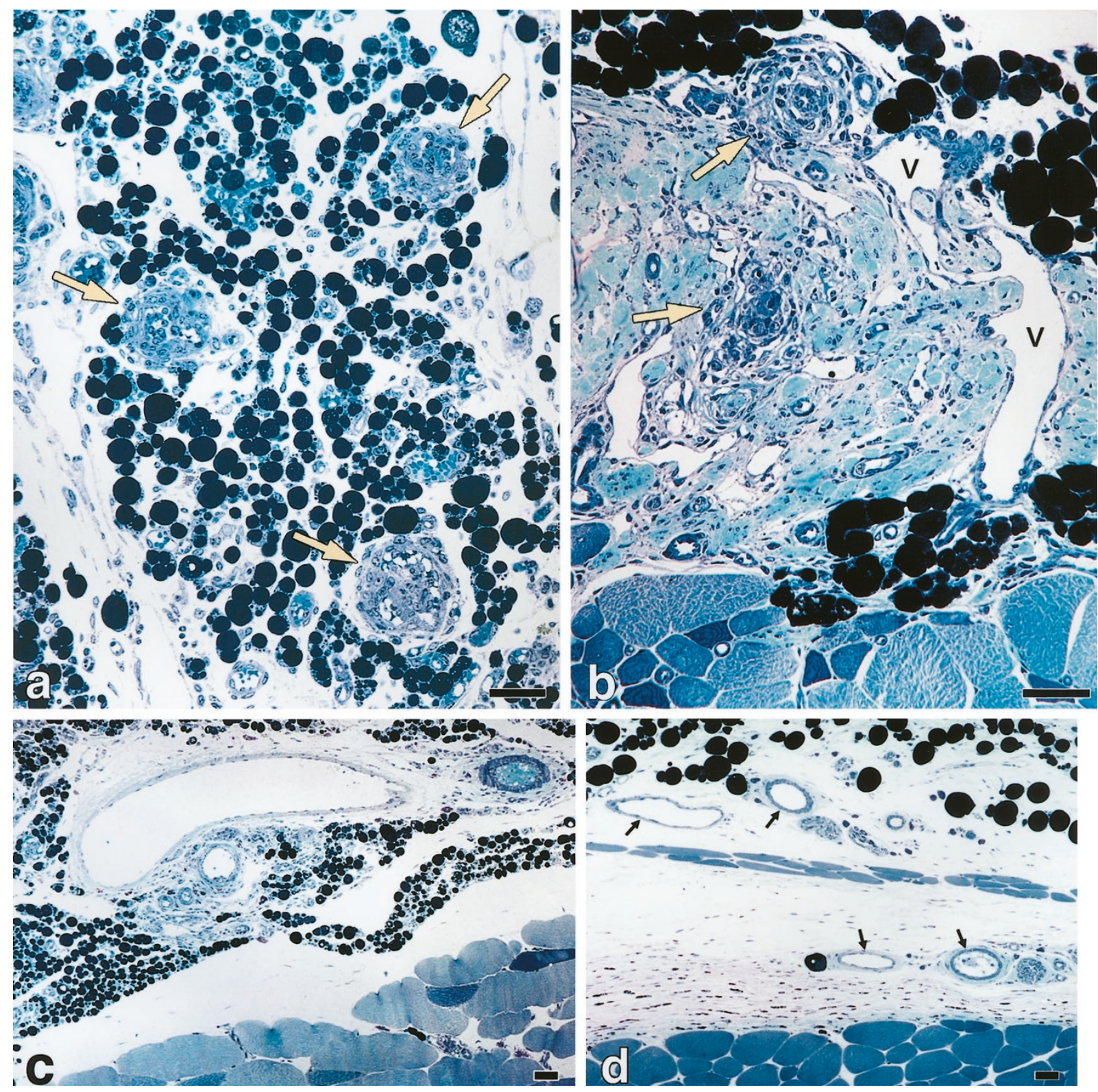

Figure 11.

One-micrometer thick, Giemsa-stained Epon sections of tissues harvested 3 (a and c), 4 (b), or 8 (d) weeks after im injection of adeno-vpf/vegf. a, Fatty tissue adjacent to leg skeletal muscle demonstrates several prominent glomeruloid bodies (yellow arrows) as well as numerous new microvessels. $b$, Residual mother vessels ( $V$ ) are enveloped by dense fibrous connective tissue, which has replaced fatty tissue adjacent to leg skeletal muscle (below). Remnants of two glomeruloid bodies are identified by yellow arrows. c and d. Medium-sized, muscular arteries and veins (indicated by arrows in d) have developed and persist in perimuscular fat, surrounded by lesser numbers of smaller vessels and fibrous connective tissue. Bars, all $50 \mu \mathrm{m}$.

VEGF has a role in arteriogenesis and therefore that collateral arteries may in some instances arise from venules or capillaries rather than from arterioles as has been widely postulated.

Finally, the results presented here for VPF/VEGFinduced angiogenesis in normal adult tissues are relevant to and provide a baseline for studies of the angiogenic response induced by various cytokines in ischemic tissues. A number of investigators have administered VPF/VEGF and other cytokines in animal models of tissue ischemia (Bauters et al, 1994; Isner et al, 1996; Laham et al, 1998; Lopez et al, 1997, 1998a, 1998b; Mack et al, 1998; Magovern et al, 1997;
Pearlman et al, 1995; Sellke et al, 1998b; Takeshita et al, 1995; Ware and Simons, 1997). More recently these approaches have been extended to patients with coronary heart disease and lower limb ischemia (Baumgartner et al, 1998; Isner et al, 1998; Losordo et al, 1998; Sellke et al, 1998a, 1998b; Van Belle et al, 1998; Witzenbichler et al, 1998). Though not yet definitive nor altogether consistent, the results have been generally interpreted as encouraging with reports of improved hemodynamics and increased capillary density. However, the kinetics of new blood vessel formation and the structure and functional capacities of the newly formed vessels induced by VPF/VEGF or other 


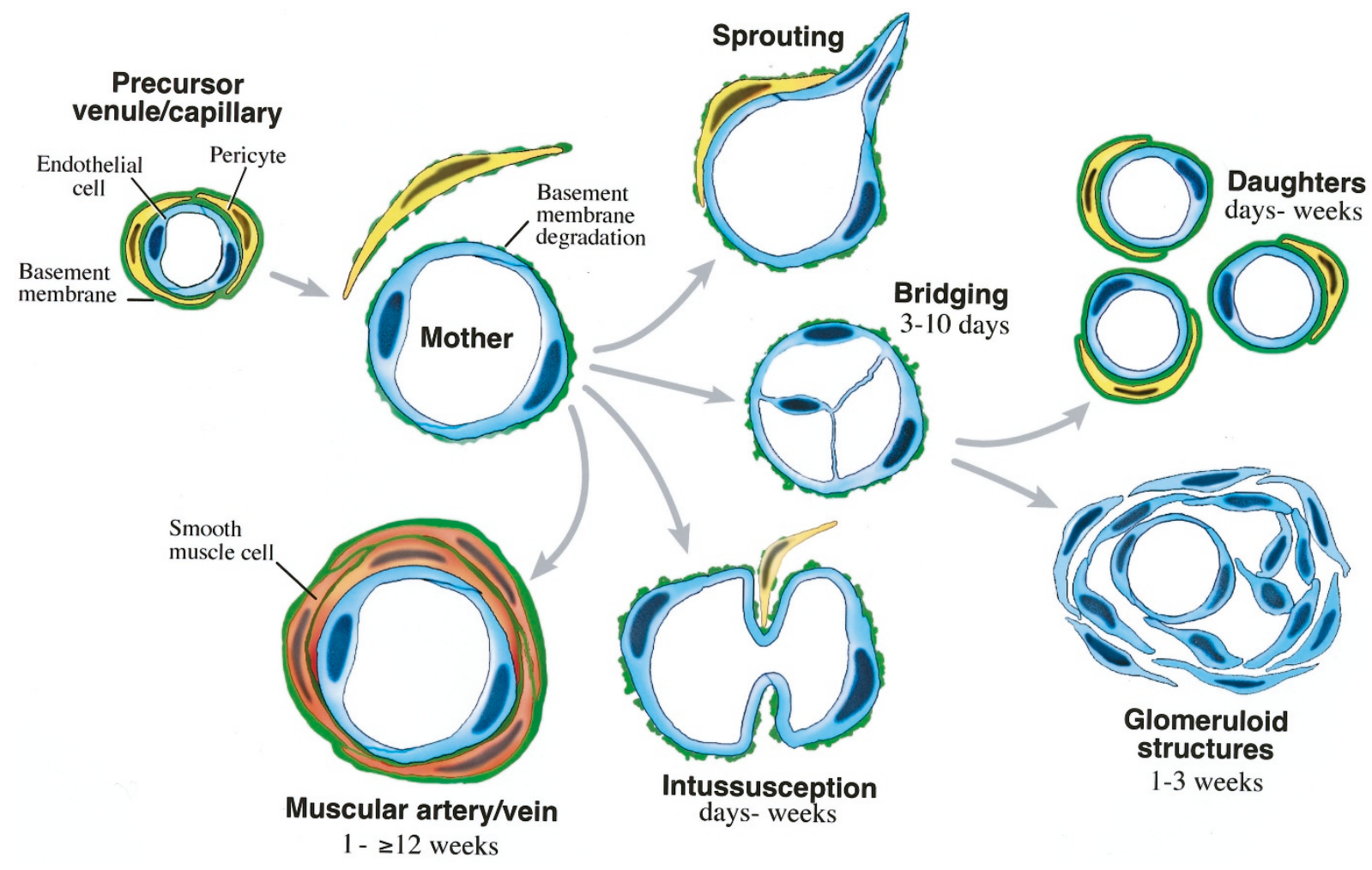

Figure 12.

Schematic diagram summarizing the progression of the angiogenic response that follows introduction of adeno-vpf/vegf into adult tissues of immunodeficient mice and rats.

cytokines in ischemic tissues have not been carefully investigated. Our results suggest that such studies will be important. The improved blood flow resulting from treatment of ischemic muscle is reported not to begin for 3 or more weeks after im administration of VPF/ VEGF protein or encoding DNA (Isner et al, 1996; Takeshita et al, 1996). At that interval the angiogenic response we induced with adeno-vpf/vegf in normoxic muscle had almost completely resolved. Moreover, even at earlier intervals when angiogenesis was maximal in skeletal muscle, the response consisted of a mixture of mother vessels and mother vessel derivatives that were embedded in tissue edema and fibrous connective tissue; these newly formed vessels provided minimal vascularization of muscle per se and would not have been expected to provide much in the way of clinical benefit. Our results do, however, suggest that VPF/VEGF can lead to the formation of mother vessels, which evolve into muscular arteries and veins. These might be of clinical benefit, and it is possible that the clinical benefits reported by others after im injection of VPFNEGF result from back leakage of injected cytokine or its encoding DNA into perimuscle fat and the evolution there of mother vessels into muscular arteries and veins.

\section{Materials and Methods}

\section{Animals and Adenoviral Vectors}

Female BALB/c ByJ Hfh11 ${ }^{\text {nu }}$ immunodeficient nude and control Balb/c mice, 4-6 weeks of age, were obtained from The Jackson Laboratory (Bar Harbor, ME); 5- 7-week-old immunodeficient nude female rats of the NIH nude (Tac:N:NIH-rnufDF) strain were obtained from Taconic (Germantown, NY). All studies were performed under hospital IRB-approved protocols.

Adenoviral vectors were prepared in which murine VPF/VEGF ${ }^{164}$, LacZ, or gfp coding sequences were inserted into the pMDM transcriptional cassette consisting of a complete immediate early cytomegalovirus promoter and intron and poly A containing sequences derived from the human beta-globin gene (Ory et al, 1996). These viruses were engineered using standard procedures (Hardy et al, 1997) and were purified by double cesium chloride banding. Immediately before injection, the virus was desalted using Quick Spin, High Capacity G-50 Sephadex columns (Boehringer Mannheim, Indianapolis, IN).

Adeno-vpf/vegf or a control insert (lacZ or gfp) was injected into different tissues: tibialis anterior muscle of the hind limb, ear or flank skin, peritoneal cavity, or myocardium (Guzman et al, 1993). Virus was administered in a volume of $10-50 \mu$ l that contained $2.5 \times 10^{8}$ pfu or dilutions thereof.

\section{Morphological Studies}

Animals were euthanized by $\mathrm{CO}_{2}$ narcosis, and tissue was harvested 1, 3, 5, or 8 days after injection. At least three animals were studied at each time point. Tissues were fixed in $10 \%$ formalin for preparation of routine, 
paraffin-embedded, hematoxylin and eosin-stained slides. In situ hybridization and immunohistochemistry of VEGFR-2 (KDR), CD-31, and fibrinogen/fibrin were performed as described previously (Brown et al, 1993). In brief, tissues were fixed in $4 \%$ paraformaldehyde in PBS, $\mathrm{pH} 7.4$, for $2-4$ hours at $4^{\circ} \mathrm{C}$. They were then transferred to $30 \%$ sucrose in PBS overnight at $4^{\circ} \mathrm{C}$, frozen in OCT compound (Miles Diagnostics, Elkhart, IN), and stored at $-70^{\circ} \mathrm{C}$. Immunohistochemistry for laminin was performed on cryostat sections of snap-frozen tissues with a rat monoclonal antibody directed against the laminin gamma 1 (B2) chain (Chemicon, Temecula, CA) (Desjardins and Bendayan, 1989). Sections were fixed in ice-cold acetone and rinsed in PBS. IgG sites were blocked with normal rabbit serum. Primary antibody was applied for 30 minutes and sections were rinsed, incubated in 3\% $\mathrm{H}_{2} \mathrm{O}_{2}$ in methanol for 15 minutes, rinsed, and incubated with biotinylated secondary antibody (horse anti-mouse lgG, $7.5 \mu \mathrm{g} / \mathrm{ml}$ ) for 30 minutes. Reaction product was developed with the avidin-biotin complex technique (Vectastain ABC elite kit; Vector Laboratories, Burlingame, $\mathrm{CA}$ ) and sections were lightly counterstained with Mayer's hematoxylin.

For $1-\mu \mathrm{m}$ thick Epon sections and for electron microscopy, tissues were fixed in paraformaldehydeglutaraldehyde, and processed as previously described (Dvorak et al, 1988). For evaluation of vascular permeability, anionic FE (cadmium free, from horse spleen; Sigma Chemical Co., St. Louis, MO) was injected iv at a dose of $1 \mathrm{mg} / \mathrm{g}$ body weight 20 minutes before euthanasia; FE is an iron-rich plasma protein that is readily visualized by electron microscopy (Feng et al, 1996).

\section{Acknowledgements}

The authors thank Drs. R. Brekken and P. Thorpe for the gift of their antibody to VEGFR-2 and Mr. Steve Moskowitz for preparing Fig. 12.

\section{References}

Aird WC, Edelberg JM, Weiler-Guettler H, Simmons WW, Smith TW, and Rosenberg RD (1997). Vascular bed-specific expression of an endothelial cell gene is programmed by the tissue microenvironment. J Cell Biol 138:1117-1124.

Asahara T, Murohara T, Sullivan A, Silver M, van der Zee R, Li T, Witzenbichler B, Schatteman G, and Isner JM (1997). Isolation of putative progenitor endothelial cells for angiogenesis. Science 275:964-967.

Baumgartner I, Pieczek A, Manor O, Blair R, Kearney M, Walsh K, and Isner JM (1998). Constitutive expression of phVEGF165 after intramuscular gene transfer promotes collateral vessel development in patients with critical limb ischemia. Circulation 97:1114-1123.

Bauters C, Asahara T, Zheng LP, Takeshita S, Bunting S, Ferrara N, Symes JF, and Isner JM (1994). Physiological assessment of augmented vascularity induced by VEGF in ischemic rabbit hindlimb. Am J Physiol 267:H1263-H1271.
Boehm T, Folkman J, Browder T, and O'Reilly MS (1997). Antiangiogenic therapy of experimental cancer does not induce acquired drug resistance. Nature 390:404-407.

Brower V (1999). Genentech enlightens other angiogenesis programs. Nat Biotechnol 17:326-327.

Brown L, Detmar M, Claffey K, Nagy J, Feng D, Dvorak A, and Dvorak H (1997). Vascular permeability factor/vascular endothelial growth factor: a multifunctional angiogenic cytokine. In: Goldberg I and Rosen E, editors. Regulation of angiogenesis. Basel, Switzerland: Birkhauser Verlag, 233-269.

Brown LF, Berse B, Jackman RW, Tognazzi K, Manseau EJ, Senger DR, and Dvorak HF (1993). Expression of vascular permeability factor (vascular endothelial growth factor) and its receptors in adenocarcinomas of the gastrointestinal tract. Cancer Res 53:4727-4735.

Brown LF, Tognazzi K, Dvorak HF, and Harrist TJ (1996). Strong expression of kinase insert domain-containing receptor, a vascular permeability factor/vascular endothelial growth factor receptor in AIDS-associated Kaposi's sarcoma and cutaneous angiosarcoma. Am J Pathol 148:1065-1074.

Brown LF, Yeo KT, Berse B, Yeo TK, Senger DR, Dvorak HF, and van de Water $L$ (1992). Expression of vascular permeability factor (vascular endothelial growth factor) by epidermal keratinocytes during wound healing. J Exp Med 176: 1375-1379.

Burri PH, and Tarek MR (1990). A novel mechanism of capillary growth in the rat pulmonary microcirculation. Anat Rec 228:35-45.

Buschmann I and Schaper W (1999). Arteriogenesis versus angiogenesis: two mechanisms of vessel growth. News Physiol Sci 14:121-125.

Chang J, Most D, Bresnick S, Mehrara B, Steinbrech DS, Reinisch J, Longaker MT, and Turk AE (1999). Proliferative hemangiomas: analysis of cytokine gene expression and angiogenesis. Plast Reconstr Surg 103:1-9; discussion 10.

Cohen MV (1985). Coronary collaterals: Clinical and experimental observations. Mt. Kisco, NY: Futura Publishing Company.

Colville-Nash PR and Willoughby DA (1997). Growth factors in angiogenesis: Current interest and therapeutic potential. Mol Med Today 3:14-23.

Dellian M, Witwer BP, Salehi HA, Yuan F, and Jain RK (1996). Quantitation and physiological characterization of angiogenic vessels in mice: effect of basic fibroblast growth factor, vascular endothelial growth factor/vascular permeability factor, and host microenvironment. Am J Pathol 149:59-71.

Desjardins M and Bendayan M (1989). Heterogenous distribution of type IV collagen, entactin, heparan sulfate proteoglycan, and laminin among renal basement membranes as demonstrated by quantitative immunocytochemistry. J Histochem Cytochem 37:885-897.

Detmar M, Brown LF, Claffey KP, Yeo KT, Kocher O, Jackman RW, Berse B, and Dvorak HF (1994). Overexpression of vascular permeability factor/vascular endothelial growth factor and its receptors in psoriasis. J Exp Med 180:1141-1146.

Drake CJ and Little CD (1995). Exogenous vascular endothelial growth factor induces malformed and hyperfused vessels during embryonic neovascularization. Proc Natl Acad Sci USA 92:7657-7661. 
Dvorak AM, Kohn S, Morgan ES, Fox P, Nagy JA, and Dvorak HF (1996). The vesiculo-vacuolar organelle (VVO): A distinct endothelial cell structure that provides a transcellular pathway for macromolecular extravasation. J Leukoc Biol 59: $100-115$.

Dvorak HF, Brown LF, Detmar M, and Dvorak AM (1995). Vascular permeability factor/vascular endothelial growth factor, microvascular hyperpermeability, and angiogenesis. Am J Pathol 146:1029-1039.

Dvorak HF, Nagy JA, Dvorak JT, and Dvorak AM (1988). Identification and characterization of the blood vessels of solid tumors that are leaky to circulating macromolecules. Am J Pathol 133:95-109.

Dvorak HF, Nagy JA, Feng D, Brown LF, and Dvorak AM (1999). Vascular permeability factor/vascular endothelial growth factor and the significance of microvascular hyperpermeability in angiogenesis. Curr Top Microbiol Immunol 237:97-132.

Feng D, Nagy J, Dvorak A, and Dvorak H (In press, 2000). Different pathways of macromolecule extravasation from hyperpermeable tumor vessels. Microvasc Res.

Feng D, Nagy J, Hipp J, Dvorak H, and Dvorak A (1996). Vesiculo-vacuolar organelles and the regulation of venule permeability to macromolecules by vascular permeability factor, histamine, and serotonin. J Exp Med 183:1981-1986.

Feng D, Nagy J, Hipp J, Pyne K, Dvorak H, and Dvorak A (1997). Reinterpretation of endothelial cell gaps induced by vasoactive mediators in guinea-pig, mouse and rat: many are transcellular pores. J Physiol (Lond) 504:747-761.

Folkman J (1995). Angiogenesis in cancer, vascular, rheumatoid and other disease. Nat Med 1:27-31.

Folkman J (1997). Angiogenesis and angiogenesis inhibition: An overview. EXS 79:1-8.

Giordano FJ, Ping P, McKirnan MD, Nozaki S, DeMaria AN, Dillmann WH, Mathieu-Costello O, and Hammond HK (1996). Intracoronary gene transfer of fibroblast growth factor-5 increases blood flow and contractile function in an ischemic region of the heart. Nat Med 2:534-539.

Grant DS and Kleinman HK (1997). Regulation of capillary formation by laminin and other components of the extracellular matrix. EXS 79:317-333.

Guzman RJ, Lemarchand P, Crystal RG, Epstein SE, and Finkel T (1993). Efficient gene transfer into myocardium by direct injection of adenovirus vectors. Circ Res 73:12021207.

Hanahan D (1998). A flanking attack on cancer. Nat Med 4:13-14.

Hardy S, Kitamura M, Harris-Stansil T, Dai Y, and Phipps ML (1997). Construction of adenovirus vectors through Cre-lox recombination. J Virol 71:1842-1849.

Henry TD (1998). Can we really grow new blood vessels? Lancet 351:1826-1827.

Isner JM and Asahara T (1999). Angiogenesis and vasculogenesis as therapeutic strategies for postnatal neovascularization. J Clin Invest 103:1231-1236.

Isner JM, Baumgartner I, Rauh G, Schainfeld R, Blair R, Manor O, Razvi S, and Symes JF (1998). Treatment of thromboangiitis obliterans (Buerger's disease) by intramuscular gene transfer of vascular endothelial growth factor: preliminary clinical results. J Vasc Surg 28:964-73; discussion 73-75.

Isner JM, Pieczek A, Schainfeld R, Blair R, Haley L, Asahara T, Rosenfield K, Razvi S, Walsh K, and Symes JF (1996). Clinical evidence of angiogenesis after arterial gene transfer of phVEGF165 in patient with ischaemic limb. Lancet 348: 370-374.

Laham RJ, Simons M, Tofukuji M, Hung D, and Sellke FW (1998). Modulation of myocardial perfusion and vascular reactivity by pericardial basic fibroblast growth factor: Insight into ischemia-induced reduction in endothelium-dependent vasodilatation. J Thorac Cardiovasc Surg 116:1022-1028.

Lantos P, VandenBerg S, and Kleihues P (1997). Tumors of the nervous system. In: Graham D and Lantos $P$, editors. Greenfield's neuropathology. London: Arnold, 583-879.

Li J, Brown LF, Hibberd MG, Grossman JD, Morgan JP, and Simons M (1996). VEGF, flk-1, and flt-1 expression in a rat myocardial infarction model of angiogenesis. Am J Physiol 270:H1803-H1811.

Lopez JJ, Edelman ER, Stamler A, Hibberd MG, Prasad P, Caputo RP, Carrozza JP, Douglas PS, Sellke FW, and Simons M (1997). Basic fibroblast growth factor in a porcine model of chronic myocardial ischemia: A comparison of angiographic, echocardiographic and coronary flow parameters. J Pharmacol Exp Ther 282:385-390.

Lopez JJ, Edelman ER, Stamler A, Hibberd MG, Prasad P, Thomas KA, DiSalvo J, Caputo RP, Carrozza JP, Douglas PS, Sellke FW, and Simons M. (1998a). Angiogenic potential of perivascularly delivered aFGF in a porcine model of chronic myocardial ischemia. Am J Physiol 274:H930-H936.

Lopez JJ, Laham RJ, Stamler A, Pearlman JD, Bunting S, Kaplan A, Carrozza JP, Sellke FW, and Simons M. (1998b). VEGF administration in chronic myocardial ischemia in pigs. Cardiovasc Res 40:272-281.

Losordo DW, Vale PR, Symes JF, Dunnington $\mathrm{CH}$, Esakof DD, Maysky M, Ashare AB, Lathi K, and Isner JM (1998). Gene therapy for myocardial angiogenesis: initial clinical results with direct myocardial injection of phVEGF165 as sole therapy for myocardial ischemia. Circulation 98:2800-2804.

Mack CA, Magovern CJ, Budenbender KT, Patel SR, Schwarz EA, Zanzonico P, Ferris B, Sanborn T, Isom P, Isom OW, Crystal RG, and Rosengart TK (1998). Salvage angiogenesis induced by adenovirus-mediated gene transfer of vascular endothelial growth factor protects against ischemic vascular occlusion. J Vasc Surg 27:699-709.

Magovern CJ, Mack CA, Zhang J, Rosengart TK, Isom OW, and Crystal RG (1997). Regional angiogenesis induced in nonischemic tissue by an adenoviral vector expressing vascular endothelial growth factor. Hum Gene Ther 8:215-227.

McKee P (1996). Pathology of the skin with clinical correlations. London: Mosby International, 16.57-16.66.

Mulliken $\mathrm{J}$ and Young A (1988). Vascular birthmarks. In: Mulliken $\mathrm{J}$ and Young $\mathrm{A}$, editors. Hemangiomas and malformations. Philadelphia: WB Saunders.

Nagy J, Morgan E, Herzberg K, Manseau E, Dvorak A, and Dvorak H (1995). Pathogenesis of ascites tumor growth: Angiogenesis, vascular remodeling and stroma formation in the peritoneal lining. Cancer Res 55:376-385. 
O’Reilly MS, Boehm T, Shing Y, Fukai N, Vasios G, Lane WS, Flynn E, Birkhead JR, Olsen BR, and Folkman J (1997). Endostatin: an endogenous inhibitor of angiogenesis and tumor growth. Cell 88:277-285.

Ory DS, Neugeboren BA, and Mulligan RC (1996). A stable human-derived packaging cell line for production of high titer retrovirus/vesicular stomatitis virus $\mathrm{G}$ pseudotypes. Proc Natl Acad Sci USA 93:11400-11406.

Paku S and Paweletz N (1991). First steps of tumor-related angiogenesis. Lab Invest 65:334-346.

Patan S, Haenni B, and Burri PH (1993). Evidence for intussusceptive capillary growth in the chicken chorioallantoic membrane (CAM). Anat Embryol (Berl) 187:121-130.

Pearlman JD, Hibberd MG, Chuang ML, Harada K, Lopez JJ, Gladstone SR, Friedman M, Sellke FW, and Simons M (1995). Magnetic resonance mapping demonstrates benefits of VEGF-induced myocardial angiogenesis. Nat Med 1:10851089.

Pepper M, Tacchini-Cottier F, Sabapathy T, Montesano R, and Wagner E (1996). Endothelial cells transformed by polyoma virus middle T oncogene: A model for hemangiomas and other vascular tumors. In: Bicknell R, Lewis C, and Ferrara N, editors. Tumor angiogenesis. Oxford: Oxford University Press.

Pepper MS, Ferrara N, Orci L, and Montesano R (1991). Vascular endothelial growth factor (VEGF) induces plasminogen activators and plasminogen activator inhibitor-1 in microvascular endothelial cells. Biochem Biophys Res Commun 181:902-906.

Plate KH, Breier G, Weich HA, and Risau W (1992). Vascular endothelial growth factor is a potential tumour angiogenesis factor in human gliomas in vivo. Nature 359:845-848.

Schaper W (1991). Angiogenesis in the adult heart. Basic Res Cardiol 86:51-56.

Schaper W and Schaper J (1993). Collateral circulation: Heart, brain, kidney, limbs. Boston: Kluwer Academic Publishers.

Sellke FW, Laham RJ, Edelman ER, Pearlman JD, and Simons M. (1998a). Therapeutic angiogenesis with basic fibroblast growth factor: technique and early results. Ann Thorac Surg 65:1540-1544.

Sellke FW, Tofukuji M, Laham RJ, Li J, Hariawala MD, Bunting S, and Simons M. (1998b). Comparison of VEGF delivery techniques on collateral-dependent microvascular reactivity. Microvasc Res 55:175-178.

Senger D, Van De Water L, Brown L, Nagy J, Yeo K-T, Yeo T-K, Berse B, Jackman R, Dvorak A, and Dvorak H (1993). Vascular permeability factor (VPF, VEGF) in tumor biology. Cancer Metastasis Rev 12:303-324.

Skalak T, Price R, and Zeller P (1998). Where do new arterioles come from? Mechanical forces and microvessel adaptation. Microcirculation 5:91-94.

Springer ML, Chen AS, Kraft PE, Bednarski M, and Blau HM (1998). VEGF gene delivery to muscle: potential role for vasculogenesis in adults. Mol Cell 2:549-558.
Strutton G (1997). Vascular tumors, ch. 38. In: Weedon D, editor. Skin pathology. Edinburgh: Churchill Livingstone, 821-854.

Swayne GT and Smaje LH (1989). Dynamic compliance of single perfused frog mesenteric capillaries and rat venules: $A$ filtration coefficient correction. Int J Microcirc Clin Exp 8:4352.

Swayne GT, Smaje LH, and Bergel DH (1989). Distensibility of single capillaries and venules in the rat and frog mesentery. Int J Microcirc Clin Exp 8:25-42.

Takahashi K, Mulliken JB, Kozakewich HP, Rogers RA, Folkman J, and Ezekowitz RA (1994). Cellular markers that distinguish the phases of hemangioma during infancy and childhood. J Clin Invest 93:2357-2364.

Takeshita S, Rossow ST, Kearney M, Zheng LP, Bauters C, Bunting S, Ferrara N, Symes JF, and Isner JM (1995). Time course of increased cellular proliferation in collateral arteries after administration of vascular endothelial growth factor in a rabbit model of lower limb vascular insufficiency. Am J Pathol 147:1649-1660.

Takeshita S, Weir L, Chen D, Zheng LP, Riessen R, Bauters C, Symes JF, Ferrara N, and Isner JM (1996). Therapeutic angiogenesis following arterial gene transfer of vascular endothelial growth factor in a rabbit model of hindlimb ischemia. Biochem Biophys Res Commun 227:628-635.

Unemori EN, Ferrara N, Bauer EA, and Amento EP (1992). Vascular endothelial growth factor induces interstitial collagenase expression in human endothelial cells. J Cell Physiol 153:557-562.

Van Belle E, Witzenbichler B, Chen D, Silver M, Chang L, Schwall R, and Isner JM (1998). Potentiated angiogenic effect of scatter factor/hepatocyte growth factor via induction of vascular endothelial growth factor: The case for paracrine amplification of angiogenesis. Circulation 97:381390.

Vikkula M, Boon LM, Carraway KL III, Calvert JT, Diamonti AJ, Goumnerov B, Pasyk KA, Marchuk DA, Warman ML, Cantley LC, Mulliken JB, and Olsen BR (1996). Vascular dysmorphogenesis caused by an activating mutation in the receptor tyrosine kinase TIE2. Cell 87:1181-1190.

Ware JA and Simons M (1997). Angiogenesis in ischemic heart disease. Nat Med 3:158-164.

Warren BA (1979). The vascular morphology of tumors. In: Peterson H-I. Tumor blood circulation: Angiogenesis, vascular morphology and blood flow of experimental and human tumors. Boca Raton, FL: CRC Press, Inc., 1-47.

Warren RS, Yuan H, Matli MR, Gillett NA, and Ferrara N (1995). Regulation by vascular endothelial growth factor of human colon cancer tumorigenesis in a mouse model of experimental liver metastasis. J Clin Invest 95:1789-1797.

Witzenbichler B, Asahara T, Murohara T, Silver M, Spyridopoulos I, Magner M, Principe N, Kearney M, Hu JS, and Isner JM (1998). Vascular endothelial growth factor-C (VEGF-C/ VEGF-2) promotes angiogenesis in the setting of tissue ischemia. Am J Pathol 153:381-394. 